\title{
Hypertensive response to raised intracranial pressure in infancy
}

\author{
A M KAISER AND A G L WHITELAW \\ Department of Paediatrics and Neonatal Medicine, Royal Postgraduate Medical School, Hammersmith \\ Hospital, London
}

SUMMARY Mean arterial pressure and intracranial pressure were measured serially in six infants with intracranial hypertension (intracranial pressure $>20 \mathrm{~mm} \mathrm{Hg}$ ), and cerebral perfusion pressure was calculated from their difference. Overall, mean arterial pressure increased with rising intracranial pressure at a mean rate of $0.20 \mathrm{~mm} \mathrm{Hg} / \mathrm{mm} \mathrm{Hg}$. This caused a fall in cerebral perfusion pressure with increasing intracranial pressure at a mean rate of $0.80 \mathrm{~mm} \mathrm{Hg} / \mathrm{mm} \mathrm{Hg}$ overall, although cerebral perfusion pressure was well maintained in one infant. Thus the rise in blood pressure was usually insufficient to compensate for the increase in intracranial pressure. In infants with acute encephalopathy vigorous blood pressure support is as important as lowering intracranial pressure.

Adequate perfusion of the brain is essential to its structural and functional integrity. Impairment of perfusion of the developing brain may have serious consequences resulting in death, or cerebral palsy with global or specific developmental retardation, blindness, spastic diplegia or quadriplegia, and fits. ${ }^{1}$ Instability of perfusion has also been implicated as a cause of intraventricular haemorrhage. ${ }^{2}$ The driving force of cerebral blood flow is the cerebral perfusion pressure, which is defined as the difference between mean arterial pressure and intracranial pressure. ${ }^{3}$ This can be expressed as: cerebral blood flow $=$ mean arterial pressure minus intracranial pressure/ cerebrovascular resistance.

Autoregulation may be defined as the process by which cerebral blood flow is maintained in the face of any alteration of cerebral perfusion pressure. ${ }^{4}$ In its absence, cerebral blood flow is proportional to cerebral perfusion pressure, and is said to be pressure passive. It is thought to occur mainly through variations in cerebral arteriolar tone ${ }^{4}$ : vasodilatation reduces cerebrovascular resistance, which tends to increase cerebral blood flow.

In the case of raised intracranial pressure, vasodilatation may act to maintain cerebral blood flow, 56 but an alternative means of compensation is available. Cushing ${ }^{7}$ first described the rise in blood pressure that occurs under these circumstances. It may be achieved by increasing cardiac output, but sympathetically mediated peripheral vasoconstriction is thought to be a more important mechanism. ${ }^{89}$
Cushing's phenomenon has been described many times in animals ${ }^{6-11}$ and older humans. ${ }^{12}$ It comprises a progressive increase in blood pressure once the intracranial pressure has attained a variable level that is approaching the resting arterial diastolic pressure..$^{6-9} 11$ At very high or sustained levels of intracranial pressure the response is exhausted, and blood pressure falls.

When both compensatory mechanisms (cerebral arteriolar dilatation and Cushing's response) operate during rises in intracranial pressure, a three step pattern of blood pressure change has been observed in experimental animals and humans. ${ }^{5610-12}$ Firstly, as the intracranial pressure rises above the normal range cerebral arteriolar vasodilatation occurs, with no change in mean arterial pressure and a steady fall in cerebral perfusion pressure; secondly, when the Cushing range is attained, the mean arterial pressure rises steadily and the cerebral perfusion pressure is maintained; and thirdly when the latter is eventually exhausted, mean arterial pressure and cerebral perfusion pressure both fall (the latter often into the negative range).

It is not known whether the Cushing response occurs in young subjects. In two studies of newborn dogs there was no increase in arterial pressure with rising intracranial pressure, ${ }^{13}{ }^{14}$ and a Cushing response was seen only in two of a series of 14 asphyxiated babies. ${ }^{15}$ A classical Cushing response, however, has been seen in newborn rabbits. ${ }^{11}$ The aim of the current study was to investigate the 
association of blood pressure and intracranial pressure in a group of infants at risk of developing intracranial hypertension in order to determine to what extent a rise in intracranial pressure was accompanied by an increase in blood pressure.

\section{Methods}

Twenty infants in the Hammersmith Hospital neonatal unit at risk of developing intracranial hypertension underwent simultaneous serial intracranial and blood pressure measurements over a two and a half year period. Only those six whose peak intracranial pressure reached $>20 \mathrm{~mm} \mathrm{Hg}$ are considered in further detail because previous work has suggested that the Cushing phenomenon only occurs when the intracranial pressure is considerably raised. The clinical characteristics of this subgroup are shown in the table. Compared with the group as a whole, they were significantly older (median 15.5 weeks compared with 3 days postnatal age) but there were no differences in birth weight or gestational age. This probably reflects the decreasing skull compliance of the older subject as the cranial sutures fuse, permitting a higher intracranial pressure to be achieved.

Blood pressure was measured from an indwelling arterial catheter when available, yielding 236 measurements. Pressure was measured by a Gaeltec transducer (Gaeltec Ltd) coupled to a Tektronix monitor (Tektronix Inc) or by a Gould transducer (Gould Statham Instruments Inc) coupled to a Medifax monitor (Cardiac Recorders Ltd) attached to the catheter. The values were accepted only when the pressure wave showed a dicrotic notch and the difference between the systolic and diastolic pressures was $>10 \mathrm{~mm} \mathrm{Hg}$; otherwise damping caused by air bubbles or blood clot was suspected and corrected. In the absence of an arterial catheter in $\mathbf{1 1 0}$ observations, an appropriately sized Dinamap cuff (Critikon Ltd) was applied to a convenient limb and blood pressure measured oscillometrically. This technique has been validated against invasive blood pressure measurement. ${ }^{16}$

Intracranial pressure was measured by connecting a Gaeltec transducer coupled to a Tektronix monitor to a cerebrospinal fluid cannula inserted for clinical indications. This was a subarachnoid catheter (Levene and Evans ${ }^{17}$ ) for 340 data points in five babies, and a ventricular cannula for six observations in one. Care was taken to exclude bubbles from the measuring circuit, to minimise leakage of cerebrospinal fluid, and to establish craniospinal communication where relevant. ${ }^{18}$ The cerebrospinal fluid wave was displayed and the pressure recorded from the digital readout using the mean if the pulse pressure was perceptible.

In babies with indwelling intracranial pressure catheters the two pressures were taken simultaneously every half to one hour. Otherwise the blood pressure was measured immediately before positioning the child for ventricular puncture, or as soon after its conclusion as required for the baby to be settled. Babies were nursed horizontally. The right atrium was used as the pressure reference point. The transducers were calibrated immediately before connection and after disconnection and at six to 12 hourly intervals in between. Cerebral perfusion pressure was calculated as the difference between mean arterial pressure and intracranial pressure.

Table Clinical details of six patients whose peak intracranial pressure reached $>20 \mathrm{~mm} \mathrm{Hg}$

\begin{tabular}{|c|c|c|c|c|c|c|c|c|}
\hline \multirow[t]{2}{*}{$\begin{array}{l}\text { Case } \\
\text { No }\end{array}$} & \multirow[t]{2}{*}{ Diagnosis } & \multirow[t]{2}{*}{$\begin{array}{l}\text { Gestation } \\
\text { (weeks) }\end{array}$} & \multirow[t]{2}{*}{$\begin{array}{l}\text { Age } \\
\text { (weeks) }\end{array}$} & \multirow{2}{*}{$\begin{array}{l}\text { Range of } \\
\text { intracranial } \\
\text { pressure } \\
\text { measurements } \\
(\mathrm{mm} \mathrm{Hg})\end{array}$} & \multirow{2}{*}{$\begin{array}{l}\text { No of } \\
\text { invasive } \\
\text { mean arterial } \\
\text { pressure } \\
\text { measurements }\end{array}$} & \multirow{2}{*}{$\begin{array}{l}\text { No of } \\
\text { oscillometric } \\
\text { mean arterial } \\
\text { pressure } \\
\text { measurements }\end{array}$} & \multicolumn{2}{|c|}{$\begin{array}{l}\text { Gradient of regression } \\
\text { lines }\end{array}$} \\
\hline & & & & & & & $\begin{array}{l}\text { Mean } \\
\text { arterial } \\
\text { pressure }\end{array}$ & $\begin{array}{l}\text { Cerebral } \\
\text { perfusion } \\
\text { pressure }\end{array}$ \\
\hline 6 & Surgical asphyxia & 39 & 26 & $6-50$ & 185 & 0 & $0 \cdot 28$ & -0.73 \\
\hline 7 & Surgical asphyxia & 32 & 5 & $5-21$ & 0 & 23 & -0.36 & $-1 \cdot 36$ \\
\hline 8 & Surgical asphyxia & 34 & 30 & $10-36$ & 0 & 44 & $1 \cdot 83$ & 0.83 \\
\hline 9 & $\begin{array}{l}\text { Asphyxia caused by } \\
\text { respiratory distress }\end{array}$ & & & & & & & \\
\hline & syndrome & 33 & $0-1$ & $7-35$ & 48 & 0 & -0.24 & $-1 \cdot 24$ \\
\hline 13 & Intracranial & & & & & & & \\
\hline & haemorrhage & 40 & 0 & $12-36$ & 3 & 37 & $-0 \cdot 08$ & $-1 \cdot 08$ \\
\hline 17 & Post haemorrhagic & & & & & & & \\
\hline & ventricular dilatation & 28 & 43 & $6-51$ & 0 & 6 & -0.21 & $-1 \cdot 21$ \\
\hline \multirow{2}{*}{\multicolumn{2}{|c|}{$\begin{array}{l}\text { Median (range) } \\
\text { Mean }\end{array}$}} & $33 \cdot 5(28-40)$ & $15 \cdot 5(0-43)$ & $18(5-51)$ & - & - & - & - \\
\hline & & - & - & - & - & - & $0 \cdot 20$ & -0.80 \\
\hline
\end{tabular}


A total of 346 observations was made, between six and 185 (median 44) for each child.

\section{Results}

The association of the dependent variables with intracranial pressure were considered separately for each subject. The only obvious correlation obtained was linear over the entire data range, rather than the three step curve described above, and fig 1 shows the best fit lines for one of the babies (case 6) recovering from operative hypoxia.

Fig 2 shows the association between mean arterial pressure and intracranial pressure in the babies in the high intracranial pressure subgroup. The gradient of the lines was close to 0 in most. The slopes ranged between -0.36 and 1.83 (mean 0.20$) \mathrm{mm} \mathrm{Hg}$ for each $\mathrm{mm} \mathrm{Hg}$ increase in intracranial pressure.

One baby (case 8) showed an exceptional rise in blood pressure with rising intracranial pressure, sufficient to maintain an increase in cerebral perfusion pressure. He was distinguished from the rest of the subgroup by being one of the oldest, and by having suffered a comparatively short and minor asphyxial insult.

Fig 3 shows that cerebral perfusion pressure fell with rising intracranial pressure in all the other five babies. The mean rate of fall in these was 1.12 (range 0.73 to 1.36 ) $\mathrm{mm} \mathrm{Hg}$ for each $\mathrm{mm} \mathrm{Hg}$ rise in

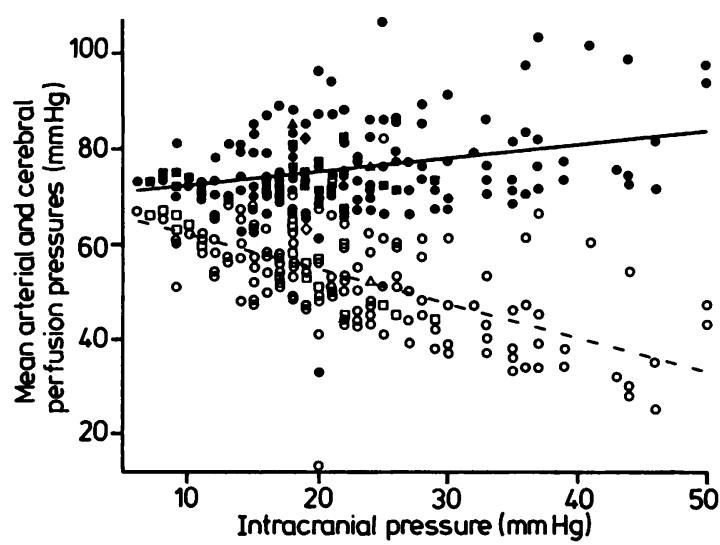

Fig 1 Correlation of mean arterial pressure (closed symbols and solid line) and cerebral perfusion pressure (open symbols and broken line) with intracranial pressure in case 6. Individual data points are represented by circles, two coincident points by squares, three by triangles and four by diamonds. The data are correlated thus: mean arterial pressure $=69 \cdot 412+0 \cdot 277$ intracranial pressure, $r=0 \cdot 289$, $p<0.001$; cerebral perfusion pressure $=69.412-0.723$ intracranial pressure, $r=-0.619, p<0.001 ; d f=183$ and $S E$ of estimate $=8 \cdot 328$ for both.

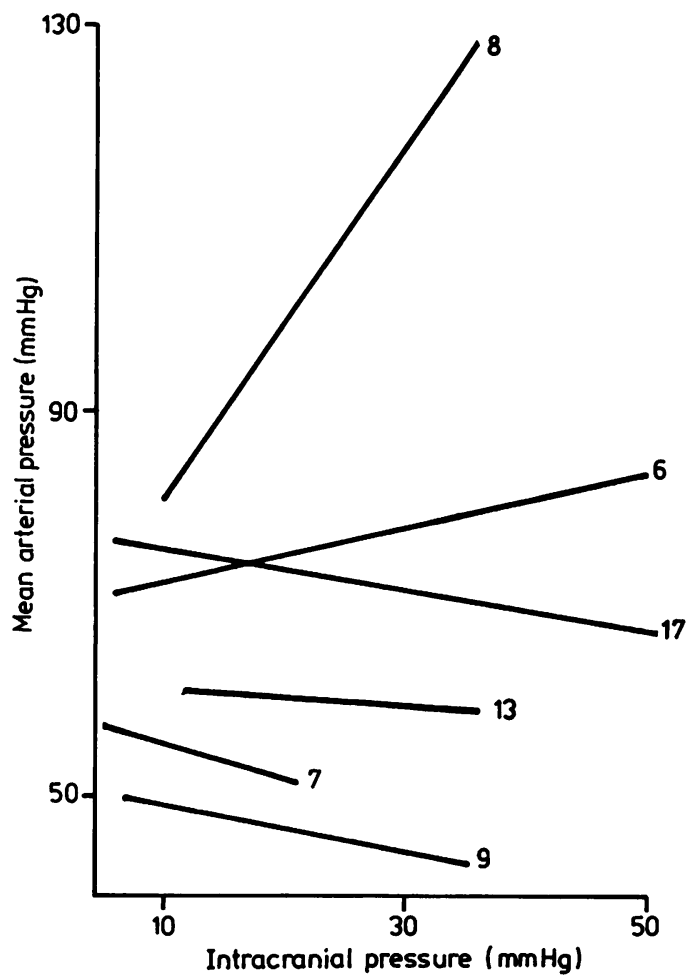

Fig 2 Regression lines of mean arterial pressure on intracranial pressure for the six patients studied.

intracranial pressure. Including all the babies, the mean rate was $0.80 \mathrm{~mm} \mathrm{Hg} / \mathrm{mm} \mathrm{Hg}$.

\section{Discussion}

In the first study of the influence of intracranial pressure on blood pressure in the human infant we have shown that mean arterial pressure and cerebral perfusion pressure have a linear correlation with intracranial pressure. The exact correlation of mean arterial pressure to intracranial pressure, however, was inconsistent and usually rose inadequately to maintain cerebral perfusion pressure.

Does this mean that the Cushing response does not occur in human infants? On one hand, intracranial pressure may not have risen high enough to elicit a Cushing response. In the current series, the peak intracranial pressure was $20-45 \mathrm{~mm} \mathrm{Hg}$ below the resting mean arterial pressure (calculated from the regression line projected back to the region where the intracranial pressure was normal). In the neonatal animal and older human, however, mean arterial pressure begins to rise only when intracra- 


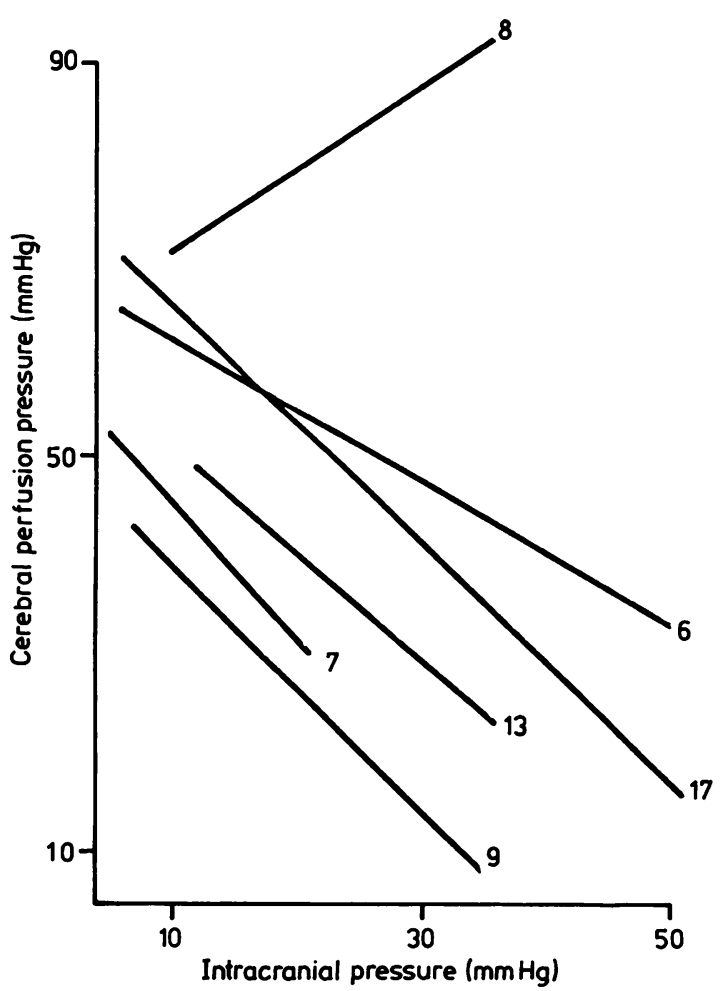

Fig 3 Regression lines of cerebral perfusion pressure on intracranial pressure for the six patients studied.

nial pressure is within $10-15 \mathrm{~mm} \mathrm{Hg}$ of it. If the human infant behaves similarly, a Cushing response would be unlikely in the intracranial pressure range achieved. On the other hand, one baby seemed to evince a Cushing response despite the intracranial pressure levels being well below resting blood pressure $(35 \mathrm{~mm} \mathrm{Hg}$ at peak intracranial pressure).

Failure of the Cushing response could occur by several mechanisms, individually or in combination. For a completed response, the following steps are necessary: detection of intracranial hypertension; afferent conduction; vasomotor centre activation; efferent (sympathetic) conduction; increase in cardiac output (by increased stroke volume or increased heart rate, or both) or increase in peripheral vascular resistance, or both. An increase in cardiac output is thought to be of minor importance in the production of the Cushing response. In the current series the finding that cardiac output often required support by colloid infusion and inotropic agents is further evidence that this mechanism is of little practical value in the infant. It is unlikely that peripheral vasomotor tone is impaired, because generalised vasoconstriction is a cardinal feature of the asphyxiated subject, one of the groups best represented in this study. It could be argued that our subjects were already maximally vasoconstricted, but they did not seem to be. Alternatively the requirement of many babies for colloid and inotropic support might have indicated a reduced cardiovascular reserve, but they subsequently seemed normovolaemic and the inotropic treatment was brief and low doses were given. This inculpates the afferent and efferent pathways and the vasomotor centre. Any of these may be impaired by the neurological insult, by the intracranial hypertension itself, or merely by their immaturity. ${ }^{11}$

The magnitude of the fall in cerebral perfusion pressure as the intracranial pressure increases is only important in so far as it might determine the level of intracranial pressure at which cerebral blood flow falls below a critical level. Goitein et $\boldsymbol{~}^{19}{ }^{19}$ suggested that cerebral perfusion pressure should be maintained above $30 \mathrm{~mm} \mathrm{Hg}$ in the first six months and $40 \mathrm{~mm} \mathrm{Hg}$ thereafter, and Raju et al ${ }^{15}$ observed in 14 asphyxiated newborns that the minimum safe level of cerebral perfusion pressure was $25 \mathrm{~mm} \mathrm{Hg}$. In our series, observed or extrapolated values of cerebral perfusion pressure fell below these levels at intracranial pressure between 11.9 and $60.2 \mathrm{~mm} \mathrm{Hg}$. Thus an intracranial pressure value at only twice the upper limit of normal of $6 \mathrm{~mm} \mathrm{Hg}{ }^{18}$ could reduce cerebral perfusion pressure by a critical amount. Such rises may occur quite readily during episodes of intracranial hypertension in the newborn.

An interesting finding in our series was that in the two infants in whom a dangerously low cerebral perfusion pressure occurred (cases 9 and 17, whose lowest cerebral perfusion pressure values were 5 and $15 \mathrm{~mm} \mathrm{Hg}$ ), the outcome was poor: they both had severe development delay with spastic quadriplegia, blindness, and fits associated with widespread cortical atrophy.

Management of the acute encephalopathies of infancy should take the anomalous behaviour of the Cushing response into account. The behaviour of the blood pressure and the intracranial pressure should be considered together in case the Cushing response is inadequate. The combination of rising intracranial pressure and falling cerebral perfusion pressure requires the vigorous support of blood pressure and reduction of intracranial pressure.

Jimmy Messeguer maintained all electronic equipment functioning perfectly at all times. We thank the resident staff for their diligence in the insertion and maintenance of arterial lines. AMK was supported by Birthright.

\footnotetext{
References

1 DeVries LS, Connell JA, Dubowitz LMS, Oozeer RC, Dubowitz V. Neurological, electrophysiological and MRI abnormali-
} 
ties in infants with extensive cystic leukomalacia. Neuropediatrics 1987;18:61-6.

2 Perlman JM, McMenamin JB, Volpe JJ. Fluctuating cerebral blood-flow velocity in respiratory-distress syndrome. $N$ Engl $J$ Med 1983;309:204-9.

3 Rowan JO, Johnston IH, Harper AM, Jennett WB. Perfusion pressure in intracranial hypertension. In: Brock $M$, Dietz $H$, eds. Intracranial pressure. New York: Springer-Verlag, 1972: 165-70.

${ }^{4}$ Lassen NA. Control of cerebral circulation in health and disease. Circ Res 1974;34:749-60.

5 Shulman K, Verdier GR. Cerebral vascular resistance changes in response to cerebrospinal fluid pressure. Am J Physiol 1967;213:1084-8.

6 Johnston IH, Rowan JO, Harper AM, Jennett WB. Raised intracranial pressure and cerebral blood flow. I. Cisterna magna infusion in primates. J Neurol Neurosurg Psychiatry 1972;35: 285-96.

7 Cushing H. Some experimental and clinical observations concerning states of increased intracranial tension. $\mathrm{Am} \mathrm{J} \mathrm{Med} \mathrm{Sci}$ 1902;124:375-400.

${ }^{8}$ Richardson TQ, Fermoso JD, Pugh GO. Effect of acutely elevated intracranial pressure on cardiac output and other circulatory factors. $J$ Surg Res 1965;5:318-22.

9 Fitch W, McDowall GD, Keaney NP, Pickerodt VWA. Systemic vascular responses to increased intracranial pressure. J Neurol Neurosurg Psychiatry 1977;40:843-52.

10 Haggendal E, Lofgren J, Nilsson NJ, Zwetnow NN. Effects of varied cerebrospinal fluid pressure on cerebral blood flow in dogs. Acta Physiologica Scand 1970;79:262-71.

11 Ogilvy CS, DuBois AB. Effect of increased intracranial pressure on blood pressure, heart rate, respiration and catecholamine levels in neonatal and adult rabbits. Biol Neonate 1987;52: 327-36.

12 Kety SS, Shenkin HA, Schmidt CF. The effects of increased intracranial pressure on cerebral circulatory functions in man. J Clin Invest 1948;27:493-9.

13 Raju TNK, Bhat R, Vidyasagar D. Age-related difference in cerebral perfusion pressure response to acute hypoxia in neonatal puppies. Biol Neonate 1982;41:258-64.

14 Batton DG, Nardis EE. The effect of intraventricular haemorrhage on cerebral blood flow in newborn dogs. Pediatr Res 1987;21:511-5.

15 Raju TNK, Vidyasagar D, Papazafiratou C. Cerebral perfusion pressure and abnormal intracranial pressure wave forms: their relation to outcome in birth asphyxia. Crit Care Med 1981;9: 449-53.

16 Frisen RH, Lichtor JL. Indirect measurement of blood pressure in neonates and infants utilizing an automatic noninvasive oscillometric monitor. Anesth Analg 1982;60:742-5.

17 Levene MI, Evans DH. Continuous measurement of subarachnoid pressure in the severely asphyxiated newborn. Arch Dis Child 1983;58:1013-5.

${ }^{18}$ Kaiser AM, Whitelaw AGL. Normal cerebrospinal fluid pressure in the newborn. Neuropediatrics 1986;17:100-2.

19 Goitein KJ, Fainmesser P, Sohmer H. Cerebral perfusion pressure and auditory brain-stem responses in childhood CNS diseases. Am J Dis Child 1983;137:777-81.

Correspondence and requests for reprints to Dr AGL Whitelaw, Department of Paediatrics and Neonatal Medicine, Hammersmith Hospital, DuCane Road, London W12 OHS.

Accepted 5 July 1988 